\title{
Human Factor Issues with Automated Mining Equipment
}

\author{
Danellie Lynas* and Tim Horberry
}

Minerals Industry Safety and Health Centre, University of Queensland, Australia

\begin{abstract}
This paper presents an extended literature review of the human factors impacts of current and future automation in the minerals industry. It begins by defining what is automation and stating why it is being developed and deployed. It then outlines why it is important to consider operators and maintainers when designing and deploying mining automation. To put mining automation into context, lessons learnt from automation in other industries and past problems with automation from a human-element perspective is then presented before specific issues in mining automation are discussed; these include 'degrees of automation', automation trends and the deployment issues. Conclusions about the human-element impacts of mining automation are made; these include the likely problems and some potential ways of reducing such problems.
\end{abstract}

Keywords: Automation, new technologies, mining, minerals industry, operator-centred design, human systems integration, human factors.

\section{INTRODUCTION}

\subsection{What is Automation?}

Automation is broadly defined as the intelligent management of a system using appropriate technology so that its operation can occur without direct human involvement [1]. In the minerals industry this is usually realized through computer-based systems and may range between component systems, which may simply involve control of a valve up to complete control systems such as a dragline or a coal preparation plant. The associated tasks required range from simple to complex. It is clear, however, that the sometime held assumption that automation replaces humans is not correct and that rather, it changes the nature of the work that humans do, often in ways unintended and unanticipated by the designers of automation.

Automation can be characterized by a continuum of levels rather than as an all-or-none concept $[1,2]$. Under full manual control, a particular function is controlled by a human with no machine control. At the other extreme, full automation, the machine controls all aspects of the function including monitoring. Different levels of automation can be identified between these two extremes.

In the mining domain, Horberry et al. [3] separate automation and new technologies into three broad categories based on system control:

- Lower level automation which includes warning systems such as proximity detection systems, and technologies that signal maintenance of equipment. In this category the operator is in full control of the system at all times and the technology provides a warning or assistance;

*Address correspondence to this author at the Minerals Industry Safety and Health Centre, University of Queensland, Australia; Tel: +61 73346 3286; E-mail: d.lynas@mishc.uq.edu.au
- $\quad$ Mid level automation which may involve removing operator control at certain times but not others, or having the operator control the equipment from a nearby location. Examples include equipment use during routine operations where the operator is a passive monitor, but takes over if intervention is deemed necessary; and line-of-sight control of underground equipment such as continuous miners, and collision detection technologies that automatically stop equipment when a collision is detected as imminent. In this category the operator is in control of the equipment at most times, but certain functions are automatically controlled by the system and overseen by the operator.

- $\quad$ Full automation which involves the operator being located remotely from the equipment and using a computer screen, joysticks, and other controls and displays.

Using such taxonomies, researchers have explored approaches that redefine the assignment of human and machine functions in terms of an integrated approach [4, 5]. The level of automation (LOA) approach seeks to optimize the assignment of control between the human and the automated system by keeping both involved in system operations [6]. Endsley \& Kaber [4] found operator situational awareness under full automation to be less than that observed under intermediate levels. In accordance with this research, other studies have shown that an intermediate LOA may be preferable to keep controller awareness at a higher level and to allow performance of critical functions $[6,7]$. Adaptive automation refers to the dynamic allocation of system control functions to a human operator and /or computer over time with the purpose of optimizing system performance. It is considered to preserve controller awareness by facilitating a better match between task demands and cognitive resources [8]. This supports previous research by Kaber \& Riley [9] where they argue operator awareness and preparedness for unexpected system states would be enhanced under such a system. 
A special type of automation for mining, tele-operation, requires further elaboration here. Tele-operation, a system with artificial sensors and actuators that allow a human to communicate with it and control it from a distance is increasingly used in mine sites, and toxic and other hazardous environments such as medical radiation. In these situations the operation is generally specialized, and specific to particular tasks such as welding or spray painting. In these situations the system is able to operate for long periods of time without human intervention, if and when interaction is required it is performed "hands on ", not from a distance. Common language and commands are essential with teleremote operation, and often haptic capability is required. Operators have reported that head-mounted displays in combination with force feedback to the controlling hand, creates a sense of telepresence whilst not actually being there [10-12] however problems have been reported with teleoperation when the communication channel contains a relatively long time delay (such as 3 seconds round trip delay). Tele-remote systems are playing a significant part in emerging automation trends in the resource industry.

\subsection{Why Automate?}

Some of the key drivers for automation (both generally, and for the minerals industry in particular) are shown below:

- Generally automation is thought to perform more efficiently, reliably and accurately than a human operator. Also, there is an expectation that the automated control system can perform a function at lower cost than the operator can. As discussed elsewhere in this paper, this assumption is often false, and human operators are needed when abnormal events occur, such as during maintenance/breakdown or when a system designer cannot automate all parts of the systems and the operator is assigned to undertake tasks to fill these gaps (Horberry et al, [3]).

- $\quad$ Safety - with higher reliability it is often argued that an automated system is safer - however system failures can lead to injuries, loss of containment of toxic or flammable materials, or catastrophic rupture of equipment resulting in significant damage to the surroundings. While mining companies are constantly looking at productivity and utilisation, safety has now come to the forefront with today's mining company CEO's judged on the mines' safety performance like never before [13].

- Time savings and efficiency -it has been argued automation can relieve humans of time-consuming and labour intensive tasks, and can reduce misuse, speed up operation, increase production rates, extend an operation to a longer shift or even to continuous production, reduce system inefficiency, ensure physical specifications are maintained and provide consistency [14]. It is also suggested that automation frees up the operator to allow them time and opportunity for long-range planning or decision making.

Other potential reasons to automate are to reduce infrastructure costs, to achieve mine accessibility and process consistency, and to counter labour shortages which are expected to become critical in the not too distant future. In general, while developed mainly for safety or efficiency reasons, automated and new technologies have been summarized into the following broad categories by Horberry et al. [3] removal of operators from hazardous situations; lower costs of production; requirements for enhanced precision (as with automated blast hole drilling); less environmental impact; ability to mine previously inaccessible areas; more data and information available and reduced manning of equipment (although as discussed previously, automation does not fully remove the human involvement).

As will be seen in the remainder of this paper, the forces driving automation appear to be coming from the four areas

- $\quad$ the corporate area (looking to optimize efficiency);

- the Original Equipment Manufacturers (looking to provide products to resource industries, and product differentiation to increase market share);

- the site workforce (technicians seeking the most efficient, reliable and least expensive solutions to their problems), and

- the technology researchers and developers (industry seeking advancement of technologies through research, development and demonstration as well as specific site problems).

\section{THE GENERAL HUMAN FACTORS APPROACH TO THE DESIGN AND INTEGRATION OF NEW TECHNOLOGIES IN THIS DOMAIN}

Similar to other industries, the human factors perspective argues that to be successful, automated systems must take into account the human element by means of user-centred design and implementation. One of the overall considerations preventing the total removal of humans from these systems has been the belief that humans are more flexible, adaptable, and creative than automation and thus better able to respond to changing or unforeseen conditions [15]. While no designer of automation can foresee all possibilities in a complex environment and one approach is to rely on the human operator to exercise their experience and judgement in using automation successful implementation requires both positive planning and an iterative approach to machine design and system processes to gain the full benefit of the technologies being developed.

Similar to findings by Horberry et al. [16] for industrial forklift trucks, operators may adapt positively or negatively to new technologies. Positive adaptation occurs when a new technology brings about a positive change in operator behaviour such as when a new speed limiting system saves fuel and increases safety whilst being acceptable and well liked by the operators. Negative adaptation may make the operators engage in more risky behaviours. Technologies that are not accepted by operators are less likely to be used properly and are more likely to be sabotaged or misused; thus any inherent potential for increasing safety or efficiency may not be fully achieved. Unless new technologies are designed effectively the information presented may create overload, distraction or even confusion to the operator. 


\section{WHAT CAN GO WRONG IN AN AUTOMATED SYSTEM?}

Automation has a long history marked by many success and equally notable failures. Automation has been defined as a device or system that performs a function previously performed by a human operator [17]. Woods [18] argues that automation does not simply supplant the person, but enables new activities, creates new roles for the person, and changes activities in unexpected ways. Lee [9] concludes that as a result, automation often results in surprises at many levels and for automation to achieve its purpose, its design must anticipate these changes. One of the ironies in automation design is that as automation increasingly supplants human control, it becomes increasingly important for designers to consider the contribution of the human operator to the system as a whole [15].

When a system fails it is often for more than one reason. In addition to purely technical failures, this often includes the human-machine interface decisions the designer made, the kinds of people operating the system, the amount of training operators received, and the level to which they are physically and mentally able to cope with the system and its changes. Additionally, systems failure can be a function of operating procedures provided for the people or the environment in which they are working.

In a variety of domains, the development and introduction of automated systems has been successfully integrated into daily operation. At the same time, however, a considerable number of unanticipated problems and failures have been observed [19], and these new and sometimes serious problems are often related for the most part to breakdowns in the interaction between human operators and automated systems. When automation is introduced to eliminate human error, the result is sometimes new and often more catastrophic errors [20]. Automation often fails to provide expected benefits because it does not simply replace the human in performing a new task, but also transforms the job and introduces a new set of tasks. Operators often then receive inadequate feedback and support in performing these new tasks. Automation also often fails because the role of the person performing the task is often underestimated, particularly their ability to compensate for the unexpected. Additionally, Sheridan [1] argues automated systems often lack the flexibility of humans needed to handle unanticipated situations. It seems likely that there will be more automation or remote teleoperation of equipment in the future. This may change the types of human factors issues involved (e.g. less manual operational tasks) but it will not remove the need for human factors involvement.

\section{LESSONS LEARNT FROM AUTOMATION IN THE NON-MINING SECTORS}

Some of the lessons learnt about new technologies from industries where automation and tele-remote operation have already been used on a large scale show that operators' jobs and tasks do change (often to a more passive role of monitoring the process rather than an active role of controller or driver of it).

\subsection{The 'Passive' Operator Problem}

There is a trend for the technology being interacted with to become increasingly more complex. Problems are created in that if a "passive operator" of an automated system loses situational awareness and /or over time becomes deskilled then they may be unable to take appropriate corrective action in the event of equipment malfunction. Other industry experience indicates that human factors issues such as how information about the status of the equipment is displayed (for operators and maintainers), how it is controlled and how acceptable it is to personnel are key issues, as well as what happens when the system malfunctions. Neglecting these issues will often result in equipment safety and performance problems, such as improper use or even sabotage, or employee distrust [3]. Equipment testing and calibration, setup, routine and emergency maintenance, and equipment control during emergencies or abnormal situations all present significant human factors concerns.

\subsection{Specific Human Factors Concerns}

In addition there are the concerns of acceptability of automation to operators, loss of situation awareness, boredom associated with what has become a vigilance task, deskilling, and operator behavioural changes with regard to different levels of automated systems and how this impacts upon risk - which is particularly important for full automation where the degree of system control by the operator is les An extensive list of human factor concerns associated with cockpit automation was complied by Funk, Lyall, and Riley [21]. Horberry et al. [3] continue this theme confirming significant human factor issues remain with equipment automation, albeit with a slightly different focus. There is now more of a focus on interface design, acceptance of new technologies, and the changing skill requirements for those who operate and maintain the new equipment rather than the traditional focus on manual tasks and environmental ergonomics. There exists the potential for automated systems to overload, confuse and distract rather than support, or assist the operator, and they highlight approaches such as standardization, appropriate training and risk assessments, alarm integration, operator and manager consultation, and input and feedback by authorities as vital components of system success.

\subsection{Operator Safety and the Benefits of a User-Centred Design Approach}

Paramount among the human factor concerns of vehicle automation are operator safety, operator workload, the trade off between high workload and high fatigue versus boredom and complacency [12]. Similar concerns were found with highway transportation [22]. Korunka and Carayon [23] and Carayon and Haims [24] demonstrated the importance of end -user involvement in the implementation of technology to the health and well-being of end users, finding that implementation of technology in an organization may have both positive and negative effects on job characteristics that ultimately affect individual outcomes (quality of working life, such as job satisfaction and stress; and perceived quality of care delivered or self-rated performance). 
Acceptance of new technologies and systems by operators is becoming seen as an increasingly important area, especially technologies which have potential to significantly enhance safety [25]. To be acceptable, these technologies must be among other things useful and satisfying to use. As seen in road transport, if such technologies are unacceptable to operators, they will not demand to have them, in which case they will not have the intended safety benefit. Even if they have them, operators may not use them if they are deemed unacceptable, or may not use them in the manner intended by the designer. A user-centred design approach can have significant benefits in improving technology acceptance by operators and drivers [25].

\subsection{Specific Concerns in Aviation}

Poor interface design, workload regulation, skill degradation, and automation-induced complacency are some of the issues that human factors professionals have reacted to in aviation automation. Compared with other humanmachine systems, aviation exhibits perhaps the most extensive degree of automation. Flight deck automation has generally been well received, yet with the advent of advanced-technology aircraft and the transfer of safetycritical functions away from human awareness and control, pilots, scientists, and aviation safety experts have expressed concerns about flight deck automation. These concerns concur with literature from other areas of automation and highlight the possibilities that automation may increase user work-load, the user may lack an understanding of automation, and that automation may be unduly complex. In addition automation related issues of trust, complacency and over reliance $[1,5]$. As the traffic controller role changes from active ("hands-on") controller to relatively passive monitor, human factor issues such as boredom, vigilance, monotony, motivation [26, 27] and stress will become progressively critical. Communication and coordination between operator and system are critical, especially in situations where the operator and the automated systems share control such as in complex flight systems. This potential problem was evident when Eastern Airlines flight 401 crashed in the Florida Everglades in the early 1970's. The pilot failed to recognize that the autopilot became disengaged while they were distracted by a faulty indicator light. While the indicator light problem was dealt with the plane was placed on autopilot and the autopilot system accidently disengaged. No one recognized it (the alarm was obscured by cockpit discussion) and the plane continued to fly on manual control without human input [28].

\subsection{An Example from Maritime Human Factors}

Another example of where automation can go wrong is the case of the Royal Majesty which ran aground en route from Bermuda to Boston in 1995. The ship had an integrated bridge system including a navigational and command system with GPS and autopilot. During the voyage the GPS antenna became detached and the ship went off course. The autonomous system onboard continued to provide information however it appeared the officers' on board had limited knowledge of, and training for the systems in place and multiple failures occurred with interpretation of the information provided [29].

\subsection{New Technology, New Tasks and New Problems}

Introducing technology invariably changes the nature of the operator's task. Often additional technology may correct the original problem, but produce other problems, not the least of which is greater complexity and less predictability and understanding by the human operators. As an example, the Three Mile Island disaster core meltdown occurred partially because operators were confused about what was happening. This in part was due to the complexity of operating the plant and illustrates that the operators could not handle the various and voluminous information from conventional alarms, indicators, and control devices during emergency conditions.

\section{CURRENT TRENDS IN MINERALS INDUSTRY AUTOMATION}

\subsection{System vs Component Level Automation}

Currently most automation effort is concentrated on the component or subsystem level providing semi-autonomous operation, and is engaged on a small scale relative to the number of mines, processing plants and export facilities in Australia. It is very difficult to retrofit automated technology to existing equipment. However, in the next five years, it is likely the integration of semi-autonomous subsystems will allow for increasing focus on automation at the equipment level. As the reliability of autonomous equipment is enhanced there will be a gradual shift of focus to the automation of unit operations. Today, various degrees of automation exist across mine sites minimal (remote operated machinery on the ground), partial (control room/subsystem- wash plant maintained by a central control room), and fully autonomous or integrated (truck, digger, rail fleet operated autonomously from a remote location off site). Researchers envisage integration of multiple pieces of equipment will eventually lead to fully autonomous operation cycles such as dig, load, haul then dump [30] and new automated equipment will be sourced as a "plug in" to the existing mine operation system.

\subsection{Early Mining Automation Work}

In mining, progress in automation began during the 1960's. Three stages of automation were identified by Konyukh [31]. The first unmanned underground mining rail carriages came into production at General Blumenthal mine in Germany in 1967, and this driverless technology was rolled out through the 1970's in Europe and the United States. Automated drills were being developed in the US at this time also. The second stage of automation involved introduction of remote-control underground ore-extraction machines in the mid -1970's. These machines were controlled by operators on the surface with the aid of two cameras. The third stage came in the mid-1990s when hard rock mines adapted some technologies developed by the coal industry. They used remote control from the surface of their load and haul machines or "boggers". Additionally, automatic shot-creting machines and rock-bolting devices became remotely controlled, however, these machines were still reliant on a human operator to guide the machine.

\subsection{The use of Scanners and Robots}

Automation in mining now uses scanners and robots extensively. Designed to function in place of humans and carry out a variety of tasks automatically or with a minimum 
of external control, utilizing integrated sensors and control systems fitted onto existing and new mining equipment they enable a machine to perform a particular task or tasks without human control [32]. Mining robots differ from those used in manufacturing processes, where components are conveyed to the robot, assembled and the product conveyed away from the robot. In mining the robot needs to move to and around the work areas to perform its task. Examples of these types of robotics are the automated Load-Haul-Dump, automated dragline swings, rope-shovels and hydraulic excavators, autonomous blast-hole drilling equipment.

Autonomous machines also need sensors to locate and orientate themselves, requiring navigation and guidance technology including lasers, mm-wave radar and computer vision for monitoring mine geometry, and stand -alone safety systems for various semi-automated activities. Examples of this technology include the system developed for underground coal mining where cutter location is determined and design pillar dimensions are maintained while ensuring maximum coal recovery; the $3 \mathrm{D}$ navigational control system for the long-wall process; and also the automated roof bolting systems. In hard rock mining a navigational system has been developed for the autonomous Load-Haul-Dump. Opinion is somewhat divided within the mining sector as to whether the future of mine automation will be directed by current surface mining technologies for application above ground - for example in the next decade it is anticipated large scale open pit automation trials will gain momentum [33] or underground mining which is not seen to be burdened by the legacy of open pit solutions and appears better positioned for the uptake of new mining technologies [34].

\subsection{Uptake of Mining Automation}

There is a general view that mining industry is slow to adopt new technologies [35], however research indicates a substantial increase in the uptake of automated and semiautomated technologies. McAree summarizes what he sees as the emerging trends for mining automation in the CRC Mining Annual Report 2009 [30]. For surface mines, he believes key activities will focus on excavation and loading, and producing outputs that incrementally deliver autonomous rock loading. For underground applications he sees key activities will be directed to to enhance situational awareness - from which the output will be an operator decision support tool that improves energy efficiency and mine vehicle safety. He indicates research and development will be undertaken with major equipment manufacturers to deliver these in a form ready for industry to use.

The current CRC Mining Automation Program has identified and addresses four gap areas they believe must be bridged for successful automation uptake: (i) control strategies must be developed to enable automated machines to operate interdependently with other equipment; (ii) situational awareness capabilities must evolve to the point where they can replace the many and varied functions performed by human operators; (iii) technologies are required that enable effective integration of automated machinery into mine systems; and (iv) workforce skills must be enhanced to support deployment of high-end automation technologies.
Much of the development work to date has been on technologies to improve the "manned mining system" but the focus now is on building the "autonomous mining system". This is largely driven by mining companies looking to increase productivity and utilization as well as safety, however as mentioned previously, other reasons to look to autonomous mining are the ability to reduce infrastructure costs, achieve process consistency and a counter measure to critical labour shortages. McAree argues "mining company employees no longer talk about the unreliability of the technologies associated with automation, mines will come to depend upon automation in profound and unspoken ways, and they can because automation works reliably, is flexible, safe and can be maintained" [36].

Recently Cunningham [37] outlined the main challenges he saw to successful implementation of automated equipment in the mining sector. These challenges varied depending on the level of infrastructure installed to cater for the equipment and mine management commitment and "buy in" across all management and staff levels, and included problems with the changing expectations on the workforce, how the work of the future would be undertaken, the challenges with introducing automation into a production environment and the acceptance of that technology within the work environment. He predicted change would not be significant over the next few years as change takes a long time to occur, but that there would be increased uptake of the currently available technologies and equipment, and more interest from mine management in change in perception of what might be possible within individual mines. An additional factor that may influence the uptake of new technologies is the lead time to develop and commercialize new equipment. In the mining sector this is often between 7 and 10 years. Many companies have a short term financial quarter focus, and more often now mines operate for less than 10 years [38].

In a different vein, Durrant Whyte [39] believes that drawing parallels from changes in other areas such as the aerospace sector over the past decade indicates that the true benefits of automation will only be fully realized through an integrated system. He believes automation will change mining in the following ways:

1. Effective use of real time information will change the mining process to a more precise and predictable operation.

2. Automation will minimize the human operator being located on site, especially in repetitive and potentially hazardous activities such as truck driving and drilling. Skilled operators, geologists and mine planners will increasingly be located remote from the site itself.

3. Mining in areas which would otherwise not be viable will become possible and mined more selectively with lower environmental impact than currently possible.

Similarly, Rio Tinto has embarked on the most extensive implementation of automation technology seen in the resource industry so far. The "Mine of the Future" program has already led to the establishment of a full-scale trial of autonomous and remotely operated equipment in the Pilbara region of Western Australia. Key automation technologies 
include the Komatsu "FrontRunner" autonomous truck dump system and the autonomous blast-hole system. Driverless trains will transport ore from the mine to the shipping port, and equipment will be managed by RioTinto's Remote Operations Centre $1300 \mathrm{~km}$ away in Perth.

Much has been written about time and cost saving aspects of the operation - absence of driver fatigue, increased safety, the ability to use the equipment in potentially unstable areas, better operations in a challenging work environment, the ability to overcome some of the lost time of blasting practices, and enhanced energy efficiency by reducing variability in the operation of the equipment. However, a major consideration in the overall success of automation in the mining sector is ensuring that those responsible for supporting the technology have the knowledge, skills and ability to do so.

The skills and knowledge requirements of the workforce of the future is outside the scope of this review, however the recent report by the Mining Industry Skills Centre's Automation for Success Report has brought to the forefront many of the issues threatening the sustainability of increased automation implementation [38]. The research is the outcome of a study undertaken by the Cooperative Research Center for Mining (CRCMining) to identify the impacts of emerging automation technologies on skill requirements for workers and maintainers of the equipment. In brief, these findings indicate a skills gap associated with automation that is expected to widen with time, that the skills and knowledge required is distinctive and not catered for by an existing framework, and that a systematic framework is required to bridge this gap. The difficulty lies in ascertaining exactly what constitutes the skills and knowledge that will be required to operate and maintain the automated equipment given the rapid technological changes in both the equipment used and the systems required to operate it.

\section{FUTURE AUTOMATION IN THE MINING SECTOR: WHERE IS IT NOW AND WHERE DOES IT NEED TO GO?}

Based on the above review, the following trends in mining automation can be discerned:

- $\quad$ An increase in distribution and scale of automation - a wider penetration of automation. Currently automation is engaged on a small scale relative to the number of mines, processing plants and export facilities in Australia.

- $\quad$ The rate of automation uptake is likely to be greatest over the next 15 years

$\bullet$

A growth in the scale of automation - currently most effort is concentrated on the component or subsystem level providing semi-autonomous operation. In five years the integration will likely allow for increasing focus on automation at the equipment level. As reliability of autonomous equipment is enhanced, there will be a gradual shift of focus to the automation of unit operations. The integration of multiple pieces of equipment will lead to fully autonomous operations cycles such as dig, load, haul and dump. Preparation must respond to the subtly changing technology focus that the different scales of automation will bring. the features and capabilities of existing devices and components is anticipated.

- Over next 15 years focus will be on 6 main technology fields: communication, sensing, computing, actuators, electronics, and safety systems.

Overall, the worldwide resource industry (at least in industrialized countries) is being transformed by its increasing use of automated technologies. At one end of the scale, this revolution is happening organically, leveraging off-the shelf technologies to incrementally improve the control of various mining processes in line with best industry practice, and the other end are some strikingly bold initiatives currently in progress to implement fully autonomous mines. Between these extremes is a spectrum of innovation that stands to profoundly change the industry over the next 15 years.

The implementation of automation must be accompanied by effort directed at supporting a company's workplace culture in their acceptance and management of the uptake of automation. The resource industry has a conservative history, and the implementation of new technology and processes must overcome a well established culture and mindset. This requires strong leadership and influence at senior management and HR level, a need to maintain resilient leadership skills, develop supervisor skills and ensure talent development processes are established as part of the progression to enable industry and sites to be prepared for change management. It is critical for personnel to understand the reasoning behind automation, both the benefits of automation now and the positive impacts this will have on the future of the resource industry. The financial costs involved in automation processes is substantial, therefore a significant level of understanding is required to provide a stable platform from which to implement the desired changes.

\section{CONCLUSIONS}

It appears from the literature that the more specific human factors problems and challenges associated with automated equipment are very similar to those encountered in other industries and in summary include (adapted and extended from Horberry et al, 2010):

- Poor operator acceptance of new technologies/automation after they are introduced.

- $\quad$ Poor human factors design of equipment.

- $\quad$ Problems with integration of multiple warnings/alarms.

- Lack of equipment standardization.

- Inadequate operator and maintainer training and support.

- Over-reliance on the technology by operators.

- Organisational issues - introducing new technology often changes the nature of the tasks to be performed, so a careful analysis of the new operational and maintenance tasks is a vital early step in ensuring that organizational issues are addressed.

- Behavioural adaptation / risk homeostasis -as found in other domains, the introduction of automation and new technologies can sometimes result in operators engaging in more risky behaviours in automated systems.

- $\quad$ Being outside of the system control loop be on the market. In addition a general advancement in 
Successful automation is more than just replacing humans with control systems to operate machines. It involves both positive planning and an iterative approach to the redesign aspects of both machines and processes to gain the full benefit of automation. The redesign must not only take into account the environment in which the machine operates and the expectations of people involved in the process, but be consultative in design with potential operators as well as engineers. It requires system integration and skill in many areas of engineering and communications as well as practical experience with mine operations to ensure requirements for robustness and intrinsic safety, equipment maintenance and operator acceptance are carefully thought through. Adopting a user-centred design process and involving operators at all stages of the technology development and deployment is the ultimate recommendation of this paper.

\section{ACKNOWLEDGEMENTS}

The authors wish to acknowledge the funding provided, and contributions made to this work, from CSIRO (Mineral Futures Cluster).

\section{CONFLICT OF INTEREST}

None Declared.

\section{REFERENCES}

[1] Sheridan T. Humans and Automation. New York: John Riley 2002

[2] Sheridan TB, Parasuraman R. Humans $v s$ automation in responding to failures: An unexpected value analysis. Hum Fact 2000; 42: 403-7.

[3] Horberry T, Burgess-Limerick R, Steiner L. Human factors for the design, operation, and maintenance of mining equipment. New York: CRC Press 2010

[4] Endsley M, Kaber DB. Level of automation effects on performance, situation awareness and workload in a dynamic control task. Ergonomics 1999; 42: 462-92.

[5] Langer-Fox J, Canty JM, Sankey MJ. Human-automation teams and adaptable control for future air traffic management. Int J Indus Ergon 2009; 39: 894-903.

[6] Kaber D, Endsley M. The effects of level of automation and adaptive automation on human performance, situation and workload in a dynamic control task. Theor Issues Ergon Sci 2009; 5: 113-53.

[7] Endsley M, Kiris EO. The out-of-the-loop performance problem and level of control in automation. Hum Fact 2005; 37: 381-94.

[8 ] Kaber DB, Riley, JM, Tan KW, Endsley MR. On the design of adaptive automation for complex systems. Int J Cogn Ergon 2001; 5(1): 137-57.

[9] Kaber DB, Riley JM. Adaptive automation of a dynamic control task based on workload assessment through a secondary monitored task. In: Proceedings of $3^{\text {rd }}$ Conference on Automation Technology and Human Performance. March 25-28, 1998 Norfolk VA.

[10] Draper J, Kaver DB, Usher JM. Telepresence. Hum Fact 1998; 40 : 354-75.

[11] Sheridan TB. Musings on telepresence and virtual presence. Teleoperators Virtual Environ - Presence 1992a; 1(1): 120-5.

[12] Sheridan TB. Telerobotics, automation and human supervisory control. Cambridge: MIT Press 1992b.

[13] Murphy 2009. In CRC Minng Annual Report 2010 [Retrieved 24 March 2011] available from http://www.crcmining.com.au/
[14] Parasuraman R, Riley VA. Humans and automation: Use, misuse, disuse, and abuse. Hum Fact 1997; 39: 230-53.

[15] Bainbridge L. Ironies of automation. New Technology and Human Error. In: Rasmussen J, Duncan K, Lepat J, Eds. Chichester, UK: Wiley 1987.

[16] Horberry T, Larsson T, Johnson I, Lambert J. Forklift safety, traffic engineering and intelligent transport systems: A case study. Appl Ergon 2004; 35: (6) 575-81.

[17] Parasuraman R, SheridanTB, Wickens CD. A model for types and levels of human interaction with automation. IEEE Trans Syst Man Cybernet 2000; SMC- 30(3): 286- 97.

[18] Woods DD, Sheridan T. Humans and automation. New York: John Riley 2002.

[19] Sarter NB, Woods DD, Billings CE. Automation surprises. In: Salvendy G, Ed. Handbook of human factors and ergonomics $2^{\text {nd }}$ ed. New York: Wiley 1997; pp. 1926- 43.

[20] Sarter NB, Woods, DD. How in the world did we ever get in that mode? Mode error and awareness in supervisory control. Hum Fact 1995; 37(1): 5-19.

[21] Funk K, Lyal, B, Wilson J, et al. Flight deck automation issues. Int J Aviat Psychol 2009; 9(2): 109-23.

[22] Barfield W, Dingus TA. Human factors in intelligent transportation systems. Mahwah, NJ, Lawrence Erlbaum Associates 1998.

[23] Korunka C, Carayon P. Continuous implementations of information technology: the development of an interview guide and a cross- national comparison of austrian and american organizations. Int J Hum Fact Manufact 1999; 9(2): 165-83.

[24] Carayon P, Haims MC. Work organization, job stress, and work-related musculoskeletal disorders. Hum Fact 1998; 4: 644-63.

[25] Regan M. Driver Acceptance of new technologies. Personal communication 2011.

[26] Hitchcock EM, Warm JS, Matthews G, et al. Automation cueing modulates cerebral blood flow and vigilance in a simulated air traffic control task. Theor Issues Ergon Sci 2003; (4): 89-112.

[27] Straussberger S, Schaefer D. Monotony in air traffic control. Air Traffic Control Quarterly, Int J Eng Operat 2007; 15: 183-207.

[28] Parasuraman R, Mouloua M, Molloy M. Reflectives of adaptive task allocation on monitoring of automated systems. Hum Fact 1996; 38 (4): 665-79.

[29] Grech M, Horberry T, Koester T. Human factors in the maritime domain. CRC 2008; 198 pages.

[30] McAree R. In CRC Mining Annual Report 2009. [Retrieved 24 $4^{\text {th }}$ March 2011] available from http://www.crcmining.com.au/

[31] Konyukh V. Robotics for Mining. Min Res Eng 2002; 11 (1): 73.

[32] Automating the Mine, CSIRO. Earthmatters Issue 19; 2009: 1-5.

[33] Bellamy, D, Pravica L. Assessing the impact of driverless haul trucks in Australian surface mining. Resources Policy. doi. 10:1016j/resourpol. 2010.09.002

[34] Goddard. D. 2011. [Retrieved on 20 January 2011] available from http://enews.miningaustralia.com.au

[35] Tilton JE. Creating wealth and competitiveness in mining. Mining Eng $2002 ; 15-22$

[36] McAree R, Lever P. In: Automation for success. Mining Industry Skills Centre Inc.

[37] Systems Challenges, Cunningham J. 2010. [Retrieved on 8 Dec 2010] available from $\mathrm{http}: / /$ enews.miningaustralia.com.au

[38] Bartos PJ. Is mining a high tech industry? Investigations into innovation and productivity advance. Resour Policy 2007; 32: 49-158.

[39] Kaupp T, Makarenko A, Durrant -Whyte HF. Human -robot communication for collaborative decision making - A probabilistic approach. Robot Autonom Syst 2010; 5(58): 444-56.

This is an open access article licensed under the terms of the Creative Commons Attribution Non-Commercial License (http: //creativecommons.org/licenses/ by-nc/3.0/) which permits unrestricted, non-commercial use, distribution and reproduction in any medium, provided the work is properly cited. 